Gut, 1985, 26, 384-392

\title{
Mechanical properties of the colon: comparison of the features of the African and European colon in vitro
}

\author{
D A K WATTERS, A N SMITH, M A EASTWOOD, K C ANDERSON, \\ R A ELTON, AND J W MUGERWA \\ From the Wolfson Laboratories, Gastrointestinal Unit, Western General Hospital and University of \\ Edinburgh; Ethicon Research Unit, Sighthill, Edinburgh; Medical Computing and Statistics Unit, University \\ of Edinburgh and Department of Pathology, Makerere University, Kampala, Uganda
}

SUMmaRY The tensile properties of the colon have been examined using methods which gave repeatable results. They showed little change after storage in salt for up to five weeks. The burst strength remained unchanged along the length of the colon. The tensile strength fell distally, as the thickness of the colonic wall increased. The width at burst decreased distally as did the internal diameter. The visco-elastic property of stress relaxation was constant in all regions. The tensile property of the colon was well developed at birth, but fell with age as did the width at burst and the internal diameter. Stress relaxation was unaffected. Because there may be a mechanical abnormality of the colonic wall in diverticular disease and as Europeans are prone to this condition while Africans are not commonly affected, European and African colons were compared. The tensile strength in a Kampala group was greater than in an Edinburgh one, but fell significantly in both groups with age. The width at burst was greater in the Kampala group, but also declined with age. Stress-relaxation was similar in both groups. In view of the similar properties in childhood of colons from Edinburgh and Kampala, the strength of the adult African compared with European colons may derive later from environmental factors such as diet. There were, however, no differences between the colons with and without diverticular disease in European subjects over the age of 50 years.

Diverticular disease is prevalent in Western countries, affecting a substantial proportion (over $30 \%$ ) of those over 60 years of age. ${ }^{1}$ Its prevalence rises with age and is most common in the sigmoid colon. ${ }^{2}$ It has been suggested that there may be a change in the physical property of the bowel wall in patients with diverticular disease as balloon distension of the distal colon in diverticular disease does not produce the volume/pressure change that occurs in normal subjects. ${ }^{34}$ Iwasaki ${ }^{5}$ found that the tensile strength of the Japanese necropsy colon declined with age. Burkitt and colleagues ${ }^{6}$ have suggested that the mechanical properties of the colon might be different in African and European subjects, as one group, the Africans, are exposed throughout life to a diet containing much more fibre resulting in bulky faeces with a fast intestinal transit and belong to a part of the world where diverticular

Address for correspondence: Mr A N Smith. Department of Surgery/Urology, Western General Hospital, Edinburgh EH4 2XU.

Received for publication 8 June 1984 disease is reputedly rare. We have examined in vitro the mechanical properties of the colon of European and African subjects to determine whether they are uniformly exhibited throughout the length of the colon, whether they change with age, and whether any possible changes predispose to the development of diverticula.

\section{Methods}

SPECIMENS

The mechanical properties of portions of the colon, 6-8 cm long, were examined at necropsy in the Edinburgh and Kampala at four sites; $5 \mathrm{~cm}$ from the ileocaecal junction, the transverse colon adjacent to the middle colic artery; the descending colon $10 \mathrm{~cm}$ below the splenic flexure and the middle of the sigmoid loop. The colon segments were washed and then preserved in salt (coarse sea salt or Analarsalt) in polyethelene bags unless tested within 24 hours when they were kept in physiological saline. The 
European colons were taken from sudden deaths at a city mortuary or in the Pathology Department, Western General Hospital, Edinburgh. The age of the 32 subjects ranged from 28 weeks gestation to over 70 years; in all 10 infant colons and 22 adult ones were examined; in five of the latter the colon was affected by diverticular disease. The bodies had been preserved at $4^{\circ} \mathrm{C}$ before necropsy.

Postmortem colons were also obtained from 17 adult and three infant African subjects in Kampala. All colons were obtained at necropsy and stored in salt for 28 days before testing. The colonic tissue was irradiated before testing to satisfy the health and safety protocols of Ethicon Laboratories, Sighthill Industrial Estate, where the testing procedure was undertaken, 2.5 megarads being delivered over nine hours in a radiocobalt plant. This amount of irradiation has been shown to change insignificantly the tensile properties of tissues. ${ }^{7}$

PREPARATION OF TISSUE FOR TESTING

The colons which had been stored in salt were rehydrated in physiological saline at $20^{\circ} \mathrm{C}$ for two to six hours. Two rings of tissue $10 \mathrm{~mm}$ wide were cut for testing in duplicate and used to measure reference dimensions.

\section{MEASUREMENT OF REFERENCE DIMENSIONS}

Three measurements were required: (1) The width: a constant $10 \mathrm{~mm}$ ring was cut out by means of a template. (2) The thickness of a piece of bowel wall was measured with a Mercer No 54 gaugemeter between two glass microscope slides. The crosssectional area of the ring was calculated on the basis of thickness and width. (3) The internal diameter of the bowel was estimated the distraction apparent as soon as stress was registered on the Instron tensiometer and is an approximation from the hemi-circumference measured (allowing for a constant error due to $\pi$ ).

\section{MECHANICAL TESTING}

An Instron 1026 tensiometer was used to test the mechanical properties of the colonic tissue. It maintained a constant strain, cycling to constant strain. The load range was from $0-50 \mathrm{~kg}$ and the minimum full scale chart deflection was from $0-50$ grams. Stainless steel hooks, $4.76 \mathrm{~mm}$ in diameter, were adapted to fit the clamp holding sockets of the tensiometer. Testing was carried out by upward movement of the hook attached to the cross-head away from the fixed lower hook.

The burst properties were tested in air at room temperature as these tests took only a few seconds so that dehydration was not a significant factor affecting the stress/strain characteristics. Visco- elastic properties were tested in physiological saline at $35-37^{\circ} \mathrm{C}$. A large plastic basin with a window insert was adapted to fit over the lower clamp socket of the Instron during these tests. The basin was filled with physiological saline from a water bath maintained and circulated at $37^{\circ} \mathrm{C}$. The circulation of saline was stopped during the actual test.

\section{MECHANICAL TESTS PERFORMED}

One of the two rings of colon was first preconditioned for 10 cycles at $30 \%$ strain, and then stress relaxation was measured for three minutes. No recovery period was allowed between preconditioning and testing. In every case the strain rate was $50 \mathrm{~mm}$ per minute.

Once the visco-elastic tests had been done the ring of colon was returned to physiological saline at $20^{\circ} \mathrm{C}$. Approximately an hour elapsed before recording the stress/strain curve to rupture.

ANALYSIS OF RESULTS

The stress relaxation curve was converted to a straight line by plotting the ratio of stress over initial peak stress against log time $(r<0 \cdot 95)$. The numeral value for stress relaxation taken for statistical comparison was the slope of this line. From the stress/strain curve to rupture, the burst strength, tensile strength and percentage elongation at burst were calculated.

\section{STATISTICAL METHODS}

Because many of the measurements were skewed, non-parametric tests were used for comparisons of groups: Wilcoxon's signed-rank test for salt versus saline storage, site differences and the effect of preconditioning: Wilcoxon's rank sum test was used for comparison of subjects aged 50 or over with and without diverticular disease. Regression analysis against age was carried out on the logarithms of the measurement values, which appeared to be approximately symmetrically distributed and regression lines for the two groups were compared by analysis of covariance. Coefficients of variation were calculated using the preconditioned and nonpreconditioned values as replicates.

The following parameters were measured: Burst strength (BS), tensile strength (TS), thickness (T), internal diameter (ID), width at burst (WB), percentage elongation (E) and stress relaxation (SR). Burst strength in grams is the force necessary to disrupt the tissue ring. It is a measure of the strength of the tissue components in the colon wall, mainly collagen. The cross-sectional area was derived as already described in $\mathrm{mm}^{2}$. The tensile strength is derived from the burst strength and the thickness of the colonic wall being a measure of 
stress per unit area and is expressed in units $\mathrm{g} / \mathrm{mm}^{2}$. The internal diameter was derived from half the circumference at stress 0 in $\mathrm{mm}$ as already described. The width at burst is the internal diameter or width of the colon in $\mathrm{mm}$ at burst. The percentage elongation was derived at burst as a \% fraction of the initial tissue width (internal diameter) and gives a measure of the stretch capacity of the tissue. The stress relaxation represents the viscoelastic property of the tissue. It is a regression slope based on a ratio and therefore has no units.

\section{Results}

THE EFFECT OF SALT STORAGE

Six colons were tested, in duplicate, once at 24 hours after overnight irradiation while in physiological saline and once at 28-35 days after salt storage followed by irradiation. Each colon was tested at the standard four sites. The means for the values of these parameters for sigmoid colon together with standard deviations are given in Table 1 . These figures suggest that salt storage for 28-35 days had little effect on the mechanical properties tested.

REPRODUCIBILITY BETWEEN ADJACENT SEGMENTS Burst strength, per cent elongation and width at burst were measured from two adjacent segments. One segment was tested for its visco-elastic properties and therefore preconditioned first, while the other was tested without preconditioning. Table 2 illustrates the reproducibility of the results. All subsequent analyses were carried out on the means of the two replicates.

VARIATION WITH SITE IN EUROPEAN AND AFRICAN COLONS

The properties of the wall of the large intestine taken from European and African subjects were examined for each segment (Table 3). The burst strength did not vary significantly throughout the colon. The cross-sectional area was not significantly
Table 2 Coefficients of variation for testing two adjacent colonic segments, one preconditioned and the other not preconditioned

\begin{tabular}{lllll}
\hline & \multicolumn{5}{l}{ Site; variation $\%$} \\
\cline { 2 - 5 } Percentage elongation & Asc & Trans & Desc & Sig \\
\hline Burst strength & 24 & 16 & 20 & 18 \\
\% Elongation & 10 & 9 & 9 & 13 \\
Width at burst & 6 & 5 & 5 & 7 \\
\hline
\end{tabular}

different from the ascending to transverse to the descending colon but these three segments showed a difference from the sigmoid colon (Table 4) $(p<0.001)$, which was thicker than the others. The tensile strength, which is dependent on crosssectional area and varies inversely with it, was less in the sigmoid area than in the other zones.

The width at burst showed significant changes between ascending and transverse versus descending and sigmoid ( $p<0.001$ in Table 4). Both sigmoid and descending colon had a reduced width at burst than the more proximal zones. The fall in the internal diameter from the proximal zones to the two distal ones was also highly significant $(p<0.001$ in Table $4)$. The percentage elongation was higher in the sigmoid but in this only differed consistently from the ascending colon. The stress relaxaton was unchanged in all four segments tested.

\section{COMPARISON OF EDINBURGH AND KAMPALA COLONS BY AGE IN ADULTS}

For each of the four regions of the colon, regression lines of each measurement (on a log scale) against age for the two racial groups were fitted to the data for subjects aged over 10 years. In no case did the slopes of the two lines differ significantly, and therefore parallel lines were fitted. Table 5 shows the parameter estimates of these lines together with the significance of slope and difference in intercept, while Figs. 1-7 show the data and fitted lines for the

Table 1 Effect of testing after salt storage or immediately in saline, for sigmoid colon only

\begin{tabular}{|c|c|c|c|c|}
\hline Burst strength (g) & BS & $1273 \pm 67$ & $1010 \pm 474$ & NS \\
\hline Tensile strength $\left(\mathrm{g} / \mathrm{mm}^{2}\right)$ & TS & $54 \pm 27$ & $45 \pm 21$ & NS \\
\hline Internal diameter $(\mathrm{mm})$ & ID & $26 \pm 10$ & $30 \pm 10$ & NS \\
\hline Width at burst (mm) & WB & $86 \pm 16$ & $83 \pm 18$ & NS \\
\hline
\end{tabular}

Figures given are mean $\pm S D, n=24$ for each group 
Table 3 Overall means and standard deviations for colonic sites by group (Edinburgh or Kampala)

\begin{tabular}{|c|c|c|c|c|c|}
\hline & & Ascending colon & Transverse colon & Descending colon & Sigmoid colon \\
\hline \multirow[t]{2}{*}{ Burst strength (g) } & Edinburgh & $1378 \pm 822$ & $1223 \pm 701$ & $1242 \pm 657$ & $1266 \pm 646$ \\
\hline & Kampala & $1799 \pm 648$ & $1687 \pm 585$ & $1638 \pm 499$ & $1618 \pm 663$ \\
\hline \multirow{2}{*}{ Cross-sectional area $\left(\mathrm{mm}^{2}\right)$} & Edinburgh & $14 \cdot 7 \pm 6 \cdot 5$ & $14 \cdot 1 \pm 6 \cdot 2$ & $14 \cdot 7 \pm 7 \cdot 4$ & $19 \cdot 0 \pm 9 \cdot 3$ \\
\hline & Kampala & $14 \cdot 3 \pm 4 \cdot 2$ & $13 \cdot 1 \pm 4 \cdot 2$ & $14 \cdot 8 \pm 5 \cdot 7$ & $16 \cdot 6 \pm 5 \cdot 9$ \\
\hline \multirow{2}{*}{ Tensile strength $\left(\mathrm{g} / \mathrm{mm}^{2}\right)$} & Edinburgh & $104 \pm 65$ & $98 \pm 57$ & $104 \pm 61$ & $81 \pm 49$ \\
\hline & Kampala & $134 \pm 56$ & $139 \pm 57$ & $127 \pm 65$ & $110 \pm 51$ \\
\hline \multirow[t]{2}{*}{ Internal diameter (mm) } & Edinburgh & $36 \pm 20$ & $30 \pm 15$ & $23 \pm 12$ & $23 \pm 13$ \\
\hline & Kampala & $49 \pm 22$ & $43 \pm 22$ & $35 \pm 15$ & $36 \pm 16$ \\
\hline \multirow[t]{2}{*}{ Width at burst (mm) } & Edinburgh & $99 \pm 48$ & $90 \pm 39$ & $70 \pm 31$ & $71 \pm 30$ \\
\hline & Kampala & $129 \pm 46$ & $108 \pm 41$ & $111 \pm 36$ & $104 \pm 33$ \\
\hline \multirow[t]{2}{*}{ Elongation $(\%)$} & Edinburgh & $206 \pm 179$ & $221 \pm 187$ & $222 \pm 125$ & $253 \pm 185$ \\
\hline & Kampala & $182 \pm 99$ & $171 \pm 122$ & $192 \pm 143$ & $235 \pm 148$ \\
\hline \multirow[t]{2}{*}{ Stress relaxation } & Edinburgh & $(0.179 \pm 0.028$ & $0 \cdot 189 \pm 0 \cdot 029$ & $0 \cdot 185 \pm 0 \cdot 020$ & $0 \cdot 188 \pm 0 \cdot 024$ \\
\hline & Kampala & $0 \cdot 162 \pm 0 \cdot 025$ & $0 \cdot 171 \pm 0 \cdot 020$ & $0 \cdot 181 \pm 0 \cdot 017$ & $0 \cdot 178 \pm 0 \cdot 019$ \\
\hline
\end{tabular}

sigmoid colon. As these figures show, the relationships were approximately linear for each measurement over the adult age range in both racial groups, and the analysis was therefore done on all adult subjects in both groups in spite of the predominance of Edinburgh subjects in the older age range.

\section{STRENGTH (Figs 1, 2)}

The burst strength fell with age in all regions except the ascending colon (Fig. 1), the Kampala colons having a greater burst strength (Table 5) in each site tested, but these differences were not quite significant. The tensile strength fell with age in all regions of the colon (Fig. 2). The Kampala group had stronger colons as shown by a regression of tensile strength against age (Table 5).
REFERENCE DIMENSIONS (Figs 3, 4)

The tendency for the cross-sectional area - that is, thickness - of the colon to rise with age (Fig. 3) was not significant. The thickness of the colon was less in the Kampala group but this was only significant $(p<0.05)$ in the sigmoid region (Table 5).

The internal diameter of the colon fell with age (Fig. 3). In adult life the distal Kampala colon was wider than in Edinburgh (descending colon $\mathrm{p}<0.05$ ) (Table 5 and Fig. 4).

\section{STRETCH (Figs. 5, 6)}

The ability of the colon to stretch as measured by the width at burst remained constant with age in the proximal colon without any racial difference. The distal colon (Fig. 5) however showed a marked tendency to have a diminished width at burst with

Table 4 Comparison of tissue taken from Edinburgh and Kampala subjects. Wilcoxon's signed rank test for site differences between measurements

\begin{tabular}{|c|c|c|c|c|c|c|c|c|c|c|c|c|c|c|}
\hline & \multicolumn{2}{|c|}{$\begin{array}{l}\text { Burst } \\
\text { strength }\end{array}$} & \multicolumn{2}{|c|}{$\begin{array}{l}\text { Cross-sectional } \\
\text { area }\end{array}$} & \multicolumn{2}{|l|}{$\begin{array}{l}\text { Tensile } \\
\text { strength }\end{array}$} & \multicolumn{2}{|l|}{$\begin{array}{l}\text { Internal } \\
\text { diameter }\end{array}$} & \multicolumn{2}{|c|}{ Width at burst } & \multicolumn{2}{|c|}{ Elongation \% } & \multicolumn{2}{|c|}{$\begin{array}{l}\text { Stress } \\
\text { relaxation }\end{array}$} \\
\hline & $E$ & $K$ & $E$ & $K$ & $E$ & $K$ & $E$ & $K$ & $E$ & $K$ & $E$ & $K$ & $E$ & $K$ \\
\hline $\mathrm{A} v \mathrm{~T}$ & NS & NS & NS & NS & NS & NS & $\mathrm{p}<0 \cdot 05$ & $\mathrm{p}<0.05$ & $\mathrm{p}<0.001$ & $\mathrm{p}<0.01$ & NS & NS & NS & NS \\
\hline $\mathrm{A} v \mathrm{D}$ & NS & NS & NS & NS & NS & NS & $\mathrm{p}<0.001$ & $\mathrm{p}<0.01$ & $\mathrm{p}<0.001$ & $\mathrm{p}<0.001$ & NS & NS & NS & $p<0.05$ \\
\hline $\mathrm{A} v \mathrm{~S}$ & NS & NS & $p<0.001$ & $\mathrm{p}<0.001$ & $\mathrm{p}<0.05$ & NS & $\mathrm{p}<0.001$ & $\mathrm{p}<0.001$ & $\mathrm{p}<0.001$ & $\mathrm{p}<0.001$ & $\mathrm{p}<0.05$ & $\mathrm{p}<0.05$ & $\mathrm{p}<0.01$ & $\mathrm{p}<0.05$ \\
\hline $\mathrm{T} v \mathrm{D}$ & NS & NS & NS & NS & NS & NS & $\mathrm{p}<0.001$ & $\mathrm{p}<0.01$ & $p<0.001$ & $\mathrm{p}<0.001$ & NS & NS & NS & NS \\
\hline $\mathrm{T} v \mathrm{~S}$ & NS & NS & $\mathrm{p}<0.001$ & $\mathrm{p}<0 \cdot 01$ & $\mathrm{p}<0.01$ & $\mathrm{p}<0.05$ & $\mathrm{p}<0.001$ & $\mathrm{p}<0.01$ & $\mathrm{p}<0.01$ & $\mathrm{p}<0.001$ & $\mathrm{p}<0.05$ & NS & NS & NS \\
\hline $\mathrm{D} v \mathrm{~S}$ & NS & NS & $\mathrm{p}<0.001$ & $\mathrm{p}<0.001$ & $\mathrm{p}<0.05$ & $\mathrm{p}<0.05$ & NS & NS & $\mathrm{p}<0.05$ & NS & NS & NS & NS & NS \\
\hline
\end{tabular}

NS $=$ not significant

$\mathrm{A}=$ ascending colon

$\mathrm{T}=$ transverse

$\mathrm{D}=$ descending

$\mathrm{S}=$ sigmoid 
Table 5 Fitted parallel regression lines of $\log _{10}$ (measurement) on age (age $>10$ )

\begin{tabular}{|c|c|c|c|c|c|}
\hline & \multicolumn{2}{|l|}{ Intercept for } & \multirow[b]{2}{*}{ Common slope } & \multicolumn{2}{|c|}{ Significance of } \\
\hline & Edinburgh & Kampala & & Slope & Difference in intercept \\
\hline \multicolumn{6}{|l|}{ Burst strength } \\
\hline Ascending & $3 \cdot 10$ & $3 \cdot 25$ & $-0 \cdot 0004$ & NS & NS \\
\hline Transverse & $3 \cdot 24$ & $3 \cdot 34$ & -0.0038 & $\mathrm{p}<0.05$ & NS \\
\hline Descending & $3 \cdot 26$ & $3 \cdot 34$ & -0.0037 & $\mathrm{p}<0.01$ & NS \\
\hline Sigmoid & $3 \cdot 24$ & $3 \cdot 32$ & -0.0033 & $\mathrm{p}<0.05$ & NS \\
\hline \multicolumn{6}{|c|}{ Cross sectional area } \\
\hline Ascending & $1 \cdot 18$ & $1 \cdot 13$ & $0 \cdot 0008$ & NS & NS \\
\hline Transverse & $1 \cdot 16$ & 1.09 & 0.0010 & NS & NS \\
\hline Descending & $1 \cdot 28$ & $1 \cdot 21$ & $-0 \cdot 0006$ & NS & NS \\
\hline Sigmoid & $1 \cdot 30$ & $1 \cdot 20$ & $0 \cdot 0009$ & NS & $\mathrm{p}<0.05$ \\
\hline \multicolumn{6}{|c|}{ Tensile strength } \\
\hline Ascending & 1.94 & $2 \cdot 12$ & -0.0013 & NS & $\mathrm{p}<0.05$ \\
\hline Transverse & $2 \cdot 08$ & $2 \cdot 25$ & $-0 \cdot 0049$ & $\mathrm{p}<0.01$ & $\mathrm{p}<0.01$ \\
\hline Descending & 1.98 & $2 \cdot 14$ & -0.0030 & NS & $\mathrm{p}<0.05$ \\
\hline Sigmoid & 1.94 & $2 \cdot 12$ & $-0 \cdot 0042$ & $\mathrm{p}<0.05$ & $\mathrm{p}<0.05$ \\
\hline \multicolumn{6}{|l|}{ Width at burst } \\
\hline Ascending & $2 \cdot 16$ & $2 \cdot 18$ & $-0 \cdot 0011$ & NS & NS \\
\hline Transverse & $2 \cdot 10$ & $2 \cdot 11$ & $-0 \cdot 0010$ & NS & NS \\
\hline Descending & 1.96 & $2 \cdot 03$ & -0.0004 & NS & $\mathrm{p}<0.01$ \\
\hline Sigmoid & $2 \cdot 06$ & $2 \cdot 15$ & -0.0024 & $\mathrm{p}<0.001$ & $\mathrm{p}<0.001$ \\
\hline \multicolumn{6}{|c|}{ Internal diameter } \\
\hline Ascending & $1 \cdot 84$ & $1 \cdot 86$ & -0.0043 & $\mathrm{p}<0.05$ & NS \\
\hline Transverse & $1 \cdot 72$ & $1 \cdot 82$ & -0.0039 & $\mathrm{p}<0.05$ & NS \\
\hline Descending & $1 \cdot 56$ & $1 \cdot 70$ & -0.0035 & $\mathrm{p}<0.05$ & $\mathrm{p}<0.05$ \\
\hline Sigmoid & $1 \cdot 62$ & 1.73 & -0.0048 & $\mathrm{p}<0.05$ & NS \\
\hline \multicolumn{6}{|c|}{ Percentage elongation } \\
\hline Ascending & $2 \cdot 05$ & $2 \cdot 04$ & 0.0046 & NS & NS \\
\hline Transverse & $2 \cdot 14$ & $2 \cdot 03$ & $0 \cdot 0041$ & NS & NS \\
\hline Descending & $2 \cdot 17$ & $2 \cdot 08$ & 0.0040 & NS & NS \\
\hline Sigmoid & $2 \cdot 23$ & $2 \cdot 21$ & 0.0034 & NS & NS \\
\hline \multicolumn{6}{|c|}{ Stress relaxation } \\
\hline Ascending & -0.83 & $-0 \cdot 85$ & 0.0013 & NS & NS \\
\hline Transverse & -0.79 & $-0 \cdot 81$ & 0.0009 & NS & NS \\
\hline Descending & -0.73 & -0.75 & $0 \cdot 0001$ & NS & NS \\
\hline Sigmoid & -0.74 & -0.77 & 0.0001 & NS & NS \\
\hline
\end{tabular}

age (sigmoid $\mathrm{p}<0.001$ in Table 5) but the Kampala subjects had a significantly greater stretch capacity in the distal colon (descending $\mathrm{p}<0.01$, sigmoid $\mathrm{p}<0.001$ ), when compared with the Edinburgh patients (Table 5). Percentage elongation showed a tendency to rise with age (Fig. 6) particularly in the Edinburgh group, but there was no significant racial difference (Table 5). The tendency to rise with age occurred because the internal diameter fell with age.

VisCoElastic PRoperties (Fig. 7)

These were similar for both racial groups and showed no tendency to change with age (Table 5). The distal colon in both racial groups had a steeper stress relaxation slope than the proximal colon (Table 4).
CHANGES IN THE COLONIC WALL DURING GROWTH As Figs. 1-7 show, the measurement values for children do not in all cases show the same linear trend with age as those for adults. The burst strength of the colons from very young Europeans and Africans is low but rises to adult values. The cross-sectional area also initially low, increases and continues to do so with age. The tensile strength is high in childhood but drops thereafter. The internal diameter is low in childhood as is the width at burst, both results being attributable directly to the mere physical size being less in the early years of life. The internal diameter is fully established, however, in adolescence and thereafter decreases as does the width at burst. The percentage elongation, low at birth, increases continuously from then onwards 


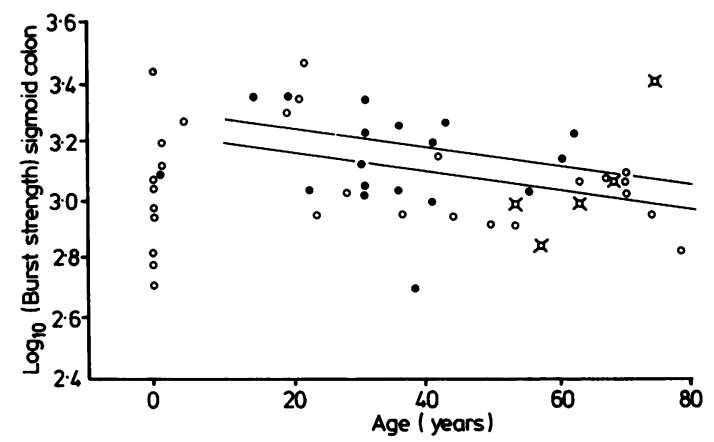

Fig. $1 \log _{10}$ burst strength against age for Edinburgh (lower line-open circles) and Kampala (upper line-closed circles). Regression slopes have been drawn parallel as there was no significant difference between them. There is a significant regression with age when both racial groups are considered together. There is no significant difference between the races though the Kampala group generally had a higher burst strength than the Edinburgh group.

Diverticular disease (in Figs. 1-7): Edinburgh subjectssuperimposed crosses on open circles.

throughout life. The stress relaxation is established at birth and does not vary from then onwards and appears to be a property which is independent of growth change. Comparison of the colonic properties in young Edinburgh and Kampala subjects by Wilcoxon's rank sums showed no significant difference between the racial groups in the limited specimens of African tissue obtained with the African values lying consistently within the

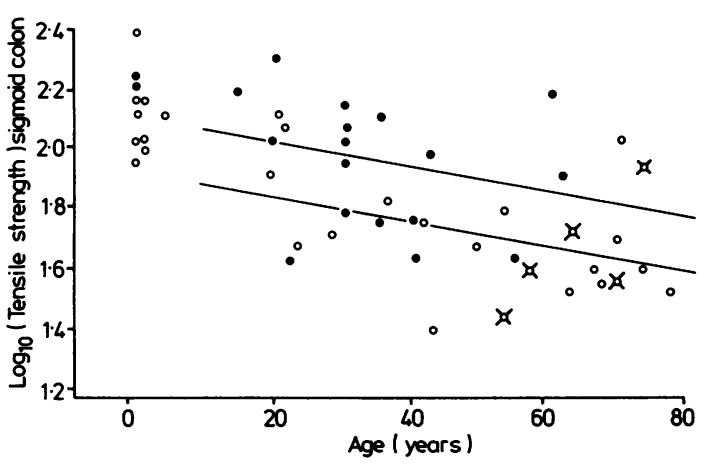

Fig. $2 \log _{10}$ tensile strength $\left(\mathrm{g} / \mathrm{mm}^{2}\right)$ against age for Edinburgh (lower line-open circles) and Kampala (upper line-closed circles) sigmoid colons. The slope of the regression is identical for both race groups and the regressions with age have been drawn parallel. The Kampala group has a significantly higher intercept with the vertical axis, representing greater tensile strength $(p<0.05)$.

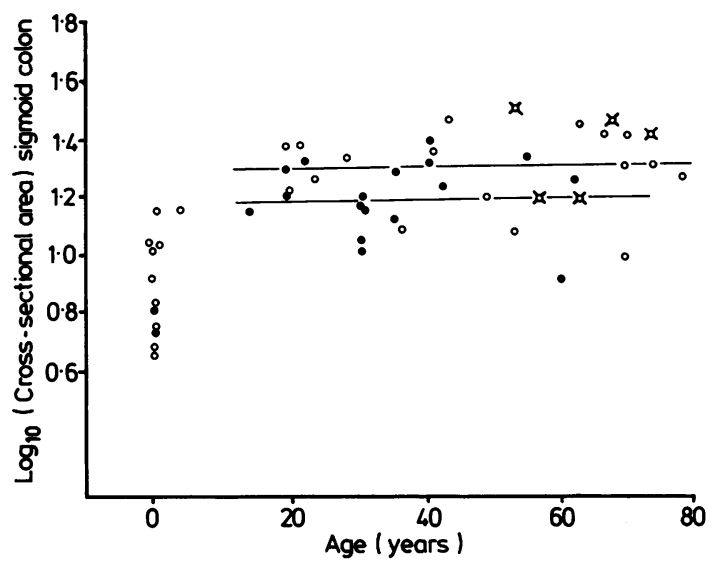

Fig. $3 \log _{10}$ cross-sectional area $\left(\mathrm{mm}^{2}\right)$ against age for the sigmoid colon. The open circles represent the Edinburgh group (upper regression line) while closed circles represent Kampala (lower regression line). In this study the width was constant $(10 \mathrm{~mm})$ so that cross-sectional area represents thickness. The trend with each group to thicken with age was not significant either when the racial groups were analysed together or separately. The Edinburgh sigmoid colon was, however, significantly thicker than the Kampala $(p<0 \cdot 05)$.

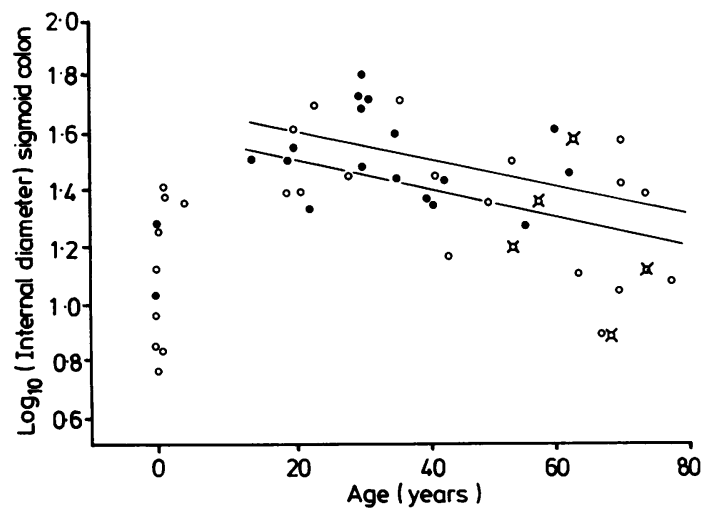

Fig. $4 \log _{10}$ internal diameter $(\mathrm{mm})$ against age for sigmoid colon from Edinburgh (open circles-lower line) and Kampala (closed circles-upper line). There was a significant regression with age in the Edinburgh group ( $p<0.01)$ but not the Kampala group. Multiple regression analysis including both groups of colons (fitted parallel lines as in Figure) showed a significant regression with age $(p<0.05)$, the Kampala colons just failed to be statistically wider than the Edinburgh. 


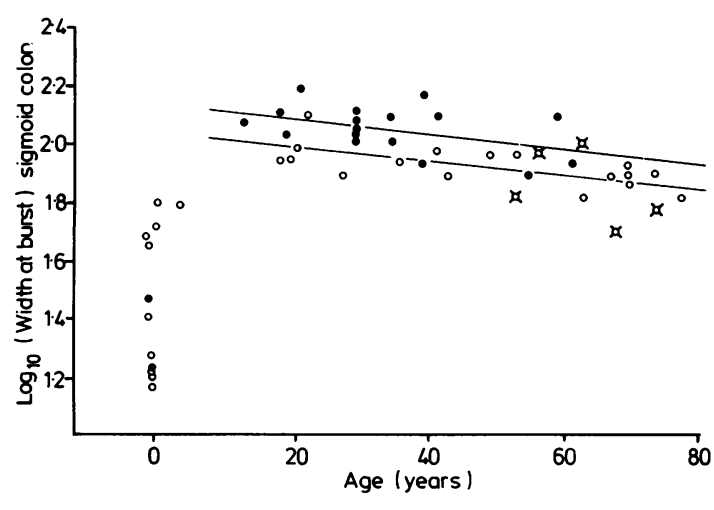

Fig. $5 \log _{10}$ width at burst $(\mathrm{mm})$ for sigmoid colon from Edinburgh (open circles - lower line) and Kampala (closed circles, upper line). The difference between racial groups was highly significant $(p<0.001)$ as was the regression with age $(p<0.001)$. The two racial groups had similar slopes, although when analysed separately, only the Edinburgh regression was statistically significant. The Kampala width at burst was the greater.

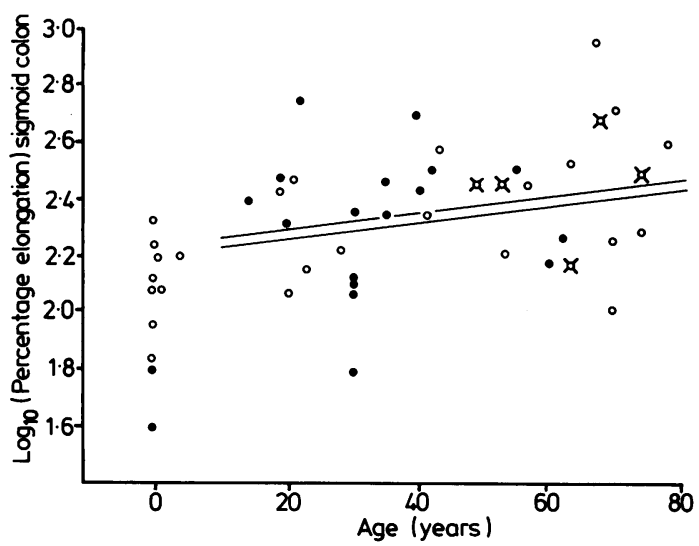

Fig. $6 \log _{10}$ percentage elongation against age for the sigmoid colon from Edinburgh (open circles-upper line) and Kampala (closed circles-lower line). There is a wide scatter of values. The increase in percentage elongation with age just fails to reach statistical significance when the colons are analysed together. When analysed separately there is a statistically significant increase for the Edinburgh colons $(p<0.05)$ but not for the Kampala ones. There was no significant differences between the races on multiple regression analysis.

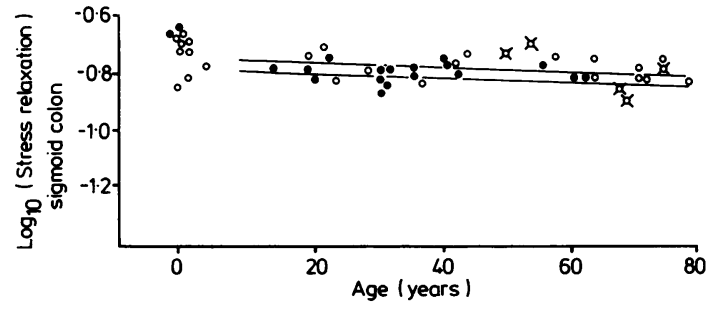

Fig. $7 \quad \log _{10}$ stress relaxation of the sigmoid colon for Edinburgh (open circles - lower regression line) and Kampala (closed circles - upper regression line). There was no significant regression with age when analysing both race groups together, nor when treating them separately.

scatter of the Edinburgh ones for each parameter measured (Figs. 1-7).

DIVERTICULAR DISEASE

These subjects did not differ significantly in any of the measurements made from other Edinburgh subjects over 50 years (Wilcoxon's rank sum test), as is apparent from Figs. 1-7 which show that the distribution of the diverticular disease results for tensile strength, internal diameter and width at burst is similar to that of the other subjects.

\section{Discussion}

The study of the mechanical properties of the bowel wall first required the development of a satisfactory method. Iwasaki ${ }^{5}$ used rectangular strips of colonic tissue but as the colon functions as a tubular structure we tested $10 \mathrm{~mm}$ rings of tissue in an attempt to be more physiological. The living colon is inaccessible for mechanical testing except by intraluminal pressure recorders, so that the only practical source of non-diseased large bowel for performing mechanical tests on the colonic wall was necropsy material. A method of storage using salt was developed to enable preservation of mechanical properties of the tissue while awaiting testing and allowing for collection and transporting of tissue from Kampala to Edinburgh for testing. The results suggest that the method is reproducible as the mechanical properties were not altered by salt storage.

The results show that the tensile strength of the colon declines with age and becomes least in the distal colon. This confirms the findings of Iwasaki, ${ }^{5}$ the only other worker who has reported on mechanical properties of the human colon. His values for tensile strength were similar to ours for each age and site studied. Tensile strength was 
calculated from the burst strength and the crosssectional area of the colon. The significantly greater tensile strength in the Kampala group was related to an increased burst strength and reduced thickness, though neither of these measurements was changed to a statistically significant extent in their own right. The standard deviations were large in many cases, suggesting great variability between individual colons. The variation between adjacent segments from the same colon was much smaller $(16-24 \%){ }^{7}$ suggesting that it was not primarily the method which gave variable results but the large individual variation.

Despite these difficulties, there was a trend for the Kampala group to be stronger, wider and thinner, thus more mechanically efficient. The possible increased thickness of the Edinburgh samples may be a means of providing for decreased strength, a greater amount of tissue being needed to compensate for the colonic work load. This difference in strength between Edinburgh and Kampala colons must be because of either genetic or environmental factors. ${ }^{8}$ Burst strength is a measure of the strongest material in the colonic wall and thus a measure of its collagen content. Cross-sectional area in this instance is a reflection of the thickness since the width was a constant $10 \mathrm{~mm}$. The thickness remained fairly constant with age, showing only a non-significant rise, and it appears that the fall in tensile strength with age is not therefore a measure of increasing thickness, but rather due to a decrease in the integrity of connective tissue. Ultrastructural techniques have demonstrated changes in collagen and other connective tissue fibres with age. ${ }^{9}$

There was a significant fall in width at burst of the distal but not proximal colon with age. There was an increase in the width of the colon at burst in both groups over the first few years of life, possibly related to growth. The width at burst remained fairly constant thereafter in the proximal colon in both groups, but the distal colon (both descending and sigmoid) had significantly lower width at burst in the Edinburgh group, though both African and European groups showed a significant fall in width at burst with age. Iwasaki $i^{5}$ also reported a declining expansibility with age because of the reduced internal diameter.

The viscoelastic property of stress relaxation was constant throughout all four regions of the colon. There was a significant rise in stress relaxation with age in the ascending colon and a significant fall in the descending colon. The changes, however, were small and it seems more likely that stress relaxation as tested by this method is unaltered by age or site. There was no consistent difference between the two groups of colons which may represent a methodological problem related to testing viscoelastic properties in dead and devascularised tissue. On the other hand the viscoelastic properties at the level of strain tested (30\%) may be similar for colons of all races and diets.

Diverticular disease is most prevalent in old age and in the distal colon. ${ }^{10}$ The findings here are consistent with this distribution. The distal colon was found to be weaker and less expansile in old age and also narrower, weaker and less expansile than the proximal one. Caro et $\mathrm{al}^{11}$ in analysing the static mechanics of a tubular structure and applying them to blood vessels showed that the circumferential stress is greater when the internal diameter is narrower and the wall is thicker. It seems therefore that the aged sigmoid colon is predisposed to develop diverticular disease both because of its ageing features and static mechnical changes. Add to this greater intraluminal pressure ${ }^{12}$ and there are ample reasons for a link between the mechanical integrity of the colonic wall and the development of diverticular disease.

The overall picture that emerged was one of a wider and possibly more distensible distal colon in the African. It is the distal colon which is the most prone to develop diverticular disease in Western countries so that the impaired stretch capacity in the Edinburgh group may reflect pre-diverticular change. Alternatively, diverticular disease may develop secondary to an impaired stretch capacity.

Some evidence which would support either of these views comes from in vivo studies of balloon distension in the human colon. Parks and Connell ${ }^{4}$ found that the sigmoid colon with diverticular disease is less able to withstand a stretching force than is the normal bowel. Parks ${ }^{13}$ later confirmed that the descending colon in those who had had their sigmoid colon resected for diverticular disease also had an impaired stretch capacity. This descending colon was probably 'pre-diverticular' in that it was noted to be free of diverticula at surgical resection of the diseased sigmoid. This was later confirmed by Smith $e$ e $\mathrm{ll}^{4}$ who also showed that subsequent treatment with bran did not lead to recovery of the faulty stretch properties of the colon.

Five of our specimens from patients over 50 years had diverticular disease and there were no significant differences between these five and eight colons from patients over 50 without diverticular disease. The similarity between the two groups suggests that the changes that occurred in the distal colon with age renders it more susceptible to diverticular disease rather than mechanical changes occurring as a result of diverticular disease. This supports the findings of Parks, ${ }^{13}$ who found that the inability of balloon distension of the distal colon in 
diverticular disease to produce a normal pressure change in response to increasing volumes was not impaired by surgical resection of the diverticular diseased area. Thus diverticular disease occurs in an area of the colon mechanically predisposed to its development. For the differences between the African and European colons, possibly the most important environmental factor is the diet, which is likely to have less fibre and more fat and sugar ${ }^{10}$ in the European group. Rats ${ }^{14}$ and rabbits ${ }^{15}$ fed long term on a low fibre, high fat diet developed colonic diverticula attributable to a weakening of the wall in relation to the pressures generated to propel faeces.

There was no apparent difference in any of the mechanical properties examined in the Edinburgh and Kampala children's colons, which implies an environmental cause for the differences in strength which develop later in life; much larger numbers would be needed, however, to prove conclusively whether environmental factors or genetic ones are responsible for the differences in strength detected in the two racial groups.

We gratefully acknowledge the help given by $\mathrm{Mr}$ Ian Capperauld, Executive Research Director, Ethicon and Dr Peter Lawrie, Chief Biologist. Our thanks are also due to Drs A D Bain, A Busuttil and R A A Macaulay of the Pathology Departments, Royal Hospital for Sick Children, and Western General Hospital, and Department of Forensic Medicine, University of Edinburgh respectively.

\section{References}

1 Eastwood MA, Eastwood J, Ward M. Epidemiology of bowel disease. In: Spiller GA, Amen RJ, eds. Fibre in human nutrition. New York and London: Plenum Press, 1976: 207-34.

2 Hughes LE. Post-mortem survey of diverticular disease of the colon. Part II: the muscular abnormality in the sigmoid colon. Gut 1969; 10: 344-51.

3 Parks TG, Connell AM. Motility studies in diverticular disease of the colon. Gut 1969; 10: 538-42.

4 Smith AN, Shepherd JJ, Eastwood MA. Pressure changes after balloon distension of the colon wall in diverticular disease. Gut 1981; 22: 841-4.

5 Iwasaki cited by Yamada. Strength of biological materials Baltimore: Williams and Watkins, 1970.

6 Burkitt DP, Walker ARP, Painter NS. Effect of dietary fibre on stools and transit-times, and its role in the causation of disease. Lancet 1972; 2: 1408-12.

7 Watters DAK. The mechanical properties of the large bowel in health and disease. Edinburgh: $\mathrm{Ch}$ M Thesis 1983.

8 Walker ARP, Walker BF, Richardson BD. Bowel transit times in Western populations. Br Med J 1970; 3: 48-9.

9 Orberg JW, Klein L, Hiltner A. Scanning electron microscopy of collagen fibres in intestine. Connect Tissue Res 1982; 9: 187-93.

10 Medical aspects of dietary fibre. $A$ report of the Royal College of Physicians of London. London: Pitman Medical, 1980.

11 Caro CG, Pedley TJ, Schroter RC, Seed WA. The mechanics of the circulation. New York; Oxford, Toronto: Oxford University Press, 1978.

12 Painter NS. Diverticular disease of the colon. London: Heinemann Medical Books, 1975.

13 Parks TG. Rectal and colonic studies after resection of the sigmoid for diverticular disease. Gut 1970; 11: 121-5.

14 Wierda JL. Diverticular of the colon in rats fed high fat diet Arch Pathol 1943; 36: 621-4.

15 Hodgson J. An animal model to study diverticular disease Br J Surg 1972; 59: 315-8. 